\title{
The Effects of Different Solid Content Carbon Nanotubes and Silver Quantum Dots on Potential Toxicity to Plants through Direct Effects on Carbon and Light Reactions of Photosynthesis
}

\author{
MARYAM SUBALYA ${ }^{1}$, RAJEEVA VOLETI $^{2}$, D. ALEXANDER WAIT ${ }^{3}$ \\ ${ }^{1}$ Department of Biochemistry and Systems Biology, Institute of System Molecular and Integrative \\ Biology, University of Liverpool, Liverpool, L69 7ZB, UK \\ ${ }^{2} 8638$ Cashio St., Los Angeles, CA 90035, USA \\ ${ }^{3}$ Department of Biology, Missouri State University, Springfield, MO 65809, USA
}

\begin{abstract}
We examined the effects of two types of carbon nanotubes (CNTs) and one type of silver quantum dot (Ag-QD) on potential plant toxicity through effects on plant gas exchange across four different experiments. First, Arabidopsis thaliana seeds were directly grown in growth medium containing $75 \%$ solid content CNTs at concentrations of $24.93 \mu \mathrm{g} / \mathrm{ml}$ and $53.55 \mu \mathrm{g} / \mathrm{ml}$ in petri dishes. Second, A. thaliana seeds were directly grown in growth medium containing $95 \%$ solid content CNTs at concentrations of $4 \mu \mathrm{g} / \mathrm{ml}$; or third, 18 $\mathrm{nm}$ Ag-QDs at a concentration of $4 \mu \mathrm{g} / \mathrm{ml}$. Fourth, we grew A. thaliana in soil for 6 weeks and added the $95 \%$ solid content CNT suspension at increasing concentrations of 10,30, 90, 150,190, $250 \mu \mathrm{g} / \mathrm{ml}$ each week. The $75 \%$ solid content CNT, and the CNTRENE ${ }^{\circledR}$ C100LM material production waste produced for disposal, had no negative effects on growth or gas exchange. We found that gas exchange in petri dish grown A. thaliana was greatly negatively affected by the Ag-QD, and relatively marginally negatively affected by the $95 \%$ solid content CNT. There were significant reductions in photosynthesis rates and related light and carbon fixation reactions in both the Ag-QD and 95\% solid content CNT A. thaliana grown in petri dishes. We found that gas exchange in soil grown A. thaliana was unaffected by $95 \%$ solid content CNTs, even at very high concentrations. These findings have implications for understanding toxicity of engineered nanoparticles on plant and animal health, public awareness, and environmental remediation.
\end{abstract}

Key-Words: - Engineered nanoparticles; plants; toxicity; photosynthesis

Received: April 12, 2021. Revised: January 7, 2022. Accepted: January 20, 2022. Published: March 3, 2022.

\section{Introduction}

Engineered nanoparticles (ENPs) are increasingly being used in consumer products and electronic devices [1-2]. Because they are so useful, more and different types are rapidly being developed and manufactured. ENPs are now found in drugs, electronic devices, and many such commonly products as sunscreens, cosmetics, health and fitness, automotive, food, home and garden, clothing, footwear, and eyeglass/lens coatings [2]. Since manufacturing of ENPs has increased [2], organisms being exposed to them in nature is inevitable, but their toxicity to organisms is not well characterized [2]. Our research focused on how three different ENPs, single walled carbon nanotubes produced with $75 \%$ or $95 \%$ solid content (hereafter, CNTs) and silver quantum dots (AgQDs), affected plant gas exchange using the model plant Arabidopsis thaliana. There is very little research on the effects of ENPs on plant gas exchange; however, negative effects on plant gas exchange could be considered as a toxic side effect and inferences on effects on higher trophic levels can be made for on-going research.

For example, it has been recommended for a decade that scientists consider plants in their studies when they track carbon nanotube (CNTs) movement in the environment [3], although standard methods and model systems are still lacking [2]. Consistent with this recommendation and recent literature [4], there is evidence that CNTs may be toxic to plants at concentrations more than $20 \mathrm{mg} / \mathrm{l}$ because of the barriers that CNT causes when they aggregate around the cells where water is delivered. As a result, they may impede the capillary action for water transportation which would result in negative effects on carbon fixation reactions, and ultimately primary and secondary plant quantity and quality.

Studies that have examined the effects of ENPs (engineered nanoparticles) on plant physiological processes provide some evidence that ENPs can have toxic effects. There are few studies, however, on the effects ENPs on plant carbon reactions. For example, a recent review on impacts of 
nanoparticles on the physiology of food crops does not provide evidence directly associated with positive, negative or neutral effects via photosynthesis [5]. Our research aims were to identify the effects of CNTs and Ag-QDs on carbon fixation rates by examining light reaction and Calvin cycle processes in A. thaliana. The data presented in this study offer new evidence on the gas exchange responses of $\mathrm{A}$. thaliana when exposed to CNTs and Ag-QDs; and, importantly, a rapid petri dish method for detecting effects was developed. The resulting information can be applied to the estimation of environmental risks related to the exposure of plants to ENPs.

CNTs were selected because they are used in high quantities in nanotechnology products and have been considered prominently in literature to evaluate their effect on plants. On the other hand; in our knowledge, Ag-QD effects on higher plant photosynthesis has not been tested, although these nanoparticles are used in applications related to increasing light absorption efficiency or have been shown to be toxic via photosynthesis in algae [6].

\section{Materials and Methods}

We examined the effects of ENPs on gas exchange in wild type Arabidopsis thaliana Columbia-0 (Col0) plants purchased from Lehle Seeds company (Waltham, Massachusetts). Three experiments were carried out in petri dishes and one in pots with soil grown in a greenhouse as follows.

\subsection{Seed and Medium Preparation for Petri Dishes Experiments}

A. thaliana seeds $(4 \mathrm{mg})$ for each petri dish were sterilized by placing them on a cone into a sterilized chamber. In a fume hood, a beaker containing bleach $(100 \mathrm{ml})$ and Hydro chloric acid (HCL) (3 $\mathrm{ml}$ ) was placed in the sterilized chamber. The sterilized chamber was kept in the fume hood for two hours to allow seeds being sterilized by the elevated chlorine gas from the beaker.

Agar (0.2g) was added into a flask, and distilled water was added for a total volume of ENP up to $5 \mathrm{ml}$ with concentrations stated below. In a separate beaker, 3-Morpholinopropane-1-sulfonic acid (MOPS) buffer $(0.225 \mathrm{~g})$ and MS salts $(0.4875 \mathrm{~g})$ were dissolved in $135 \mathrm{ml}$ of distilled water. The $\mathrm{pH}$ of the solution was adjusted to 7.0 by adding $100 \mathrm{ml}$ of $\mathrm{mM} \mathrm{KOH}$ and distilled water in a final volume of $180 \mathrm{ml}$. The solution $(20 \mathrm{ml})$ was added to flasks containing agar. Flasks were autoclaved at $121{ }^{\circ} \mathrm{C}$ for 20 minutes. Agar flasks were then placed in warm water bath set at $55^{\circ} \mathrm{C}$. For flasks with water only, nanoparticle was added to each flask. Flasks with unsterilized nanoparticles were supplemented with Amphotericin B and carbencillin to avoid bacterial or fungal contamination. The flasks were sonicated, and the agar containing flasks were poured into the flasks that contain the mixed nanoparticle with distilled water and held in the water in the sonicator to make sure that nanoparticles were evenly distributed within the medium. After 2 minutes, the flask composition was poured into plates and left to cool at room temperature.

Seeds were sprinkled evenly onto each petri dish plate. The plates were sealed with parafilm and then placed in a refrigerator. After 3 days, the plates were taken out of the refrigerator and the parafilm was removed from each plate. An open zip-lock bag was used to cover the plates to prevent water loss from the medium or bacteria or fungi growth in the medium. The plates finally were placed in the growth chamber (Conviron Model Adaptis A1000AR Chamber) at $21^{\circ} \mathrm{C}, 150 \mu \mathrm{mol} \mathrm{m} \mathrm{m}^{-2} \mathrm{~s}^{-1}$, short day cycle (10 hours light and 14 hours dark). Plates were rotated randomly each day within the growth chamber to avoid the difference effect associated with plate position within the chamber.

In the first experiment, we used a CNT suspension that contained $\geq 75 \%$ CNTs of average length of $\sim 0.4-0.6 \mu \mathrm{m}$ manufactured by arc discharge method obtained from Brewer Science, Rolla, Missouri. These CNTs are of low ion content and have pure CNT fabric without any polymers. Therefore, these CNTs can be easily suspended in water-based formulations without forming aggregates. We used these CNTs at concentrations of $135 \mu \mathrm{g} / \mathrm{ml}$ and $290 \mu \mathrm{g} / \mathrm{ml}$, which when mixed with a plant growth medium were at a final concentration of 24.93 and $53.55 \mu \mathrm{g} / \mathrm{ml}$ in petri dishes on MS (Murashige and Skoog) medium. At three different growth days (14, 22, and 30), physiological and growth measurements were recorded for all sets of a petri dishes. Only significant effects throughout the entire growth period are reported, otherwise we considered there to be no negative or positive effects.

In the second and third experiment single wall carbon nanotubes; purity $>95 \%$, diameter $1.5 \mathrm{~nm}$, length 1-5 microns, and surface area 1020.48 M2/gram obtained from Nanolab; and, Ag-QDs, diameter $18.5 \pm 3.4 \mathrm{~nm}$, surface area $29.0 \mathrm{~m}^{2} / \mathrm{g}$, and Ag mass concentration $0.021 \mathrm{mg} / \mathrm{Ml}$ obtained from $20 \mathrm{~nm}$ Pelco $^{\circledR}$ Citrate NanoXact ${ }^{\mathrm{TM}}$ Silver were assayed. In this second and third experiment, $A$. thaliana was again grown in petri dishes (three 
replicates of controls, CNTs $(4 \mu \mathrm{g} / \mathrm{ml})$, and Ag-QDs $(4 \mu \mathrm{g} / \mathrm{ml})$ ) on MS (Murashige and Skoog) medium. At three different growth days $(14,22$, and 30), measurements were recorded for all sets of a petri dishes as stated above.

\subsection{Greenhouse Experiment}

In the fourth experiment for the $95 \%$ content CNT added to soil we first plated A. thaliana seeds on $500 \mu \mathrm{l}$ of $0.08 \%$ agar poured into six microcentrifuge tubes. The tubes were covered with tin foil and kept in a refrigerator for two days. To prepare soil for planting, we filled a pot with mixed potting soil that was obtained from Sun-Gro® Horticulture (San Diego, California). We washed the soil with water to remove fungi and other materials that might exist in the soil as described by Lehle Seeds instructions. This step was repeated three times, and then the soil was left soil to dry. After the cleaning process, potting soil was placed Arraysystem pots, and five seedlings were transferred from the gel to the soil. We grew Arabidopsis using Arasystem which is designed by Arasystem for Arabidopsis. This system included tray, pots, baskets, inverted cons, and con tubes. Some advantages of this system are that it reduces the effects of plant competition and enhances plant growth. Thirty-six pots were used for planting $A$. thaliana (18 replicate pots were prepared for controls and 18 replicate treatments of CNTs). We added five seeds per pot, covered the pots and tray with plastic, and grew A. thaliana on benches under photosynthetically active radiation of $150 \mu \mathrm{mol} \mathrm{m}{ }^{-2}$ $\mathrm{s}^{-1}$ and under a cycle of 11 hours light/13hours dark. After two weeks of germination, we reduced the number of seedlings in each basket to two plants. The plants were fertilized once a week until harvest. The baskets were moved around randomly to minimize the effect of confounding variables that might interact with the treatment.

\subsection{Gas Exchange, Carbon and Light Reactions}

Gas exchange was measured using a LI-6400XT Portable Photosynthesis System equipped with 6 $\mathrm{cm}^{2}$ leaf chamber (Li-Cor, Lincoln, NE, USA). Flow rate in chamber was set to $300 \mu \mathrm{mol} \mathrm{s}{ }^{-1}$ and flow speed set to slow. Block temperature was controlled to be as same as leaf temperature. For light curve measurements, data were recorded at three light level $\left(150,500,0 \mu \mathrm{mol} \mathrm{m}^{-2} \mathrm{~s}^{-1}\right.$ respectively) and $\mathrm{CO}_{2}$ mixture of reference was maintained at $400 \mu \mathrm{mol}$ $\mathrm{CO}_{2}$ moll $^{-1}$ air. On the other hand, $\mathrm{CO}_{2}$ level was set at 400,700 , or $0 \mu \mathrm{mol} \mathrm{CO}_{2} \mathrm{~mol}^{-1}$ air, and light intensity was maintained at $500 \mu \mathrm{mol} \mathrm{m} \mathrm{m}^{-2} \mathrm{~s}^{-1}$ for A-
$\mathrm{Ci}$ curve measurements. Leaf area was set depending on how much of chosen A. thaliana sample filled the space of the Licor cuvette.

A curve fitting program, which is available online for free with instructions for use, was used to estimate variables associated with light and Calvin cycle reactions [see 16]. For light response curves, the users needs to enter $\mathrm{T}$ leaf (leaf temperature), $\mathrm{P}_{\mathrm{atm}}$ (atmospheric pressure), Rd (day respiration), ambient $\mathrm{O}_{2}, \mathrm{~g}_{\mathrm{m}}$ values, A (photosynthesis rate), $\mathrm{Ci}$ (intracellular concentration) and light intensity. The mean values of $\mathrm{T}$ leaf, photosynthesis rate, intracellular $\mathrm{CO}_{2}$ concentration, which were recorded by the Licor for each treatment in each day, were entered in this Excel sheet. Light intensity $\left(0,150\right.$, and $\left.500 \mu \mathrm{mol} \mathrm{m}^{-2} \mathrm{~s}^{-1}\right)$ was assigned next to each data point. $\mathrm{Rd}$ was assigned as the data points measured at the lowest light intensity ( $\mathrm{PAR}=0 \mu \mathrm{mol}$ $\left.\mathrm{m}^{-2} \mathrm{~s}^{-1}\right) . \mathrm{P}_{\mathrm{atm}}=101.3 \mathrm{kPa}$ at 0 elevation, $\mathrm{O}_{2}=21 \mathrm{kPa}$, and $\mathrm{g}_{\mathrm{m}}=2 \mu \mathrm{mol} \mathrm{m} \mathrm{m}^{-2} \mathrm{~s}^{-1} \mathrm{~Pa}^{-1}$ were kept constant for all treatments; note that it is better to indicate $\mathrm{g}_{\mathrm{m}}$ values that were directly measured or estimated by other methods. This program estimates Jmax (electron transport rate at highest light level), $\Phi>=$ 0.5 (initial slop for modeled $\mathrm{J}$ ), and $\Theta>=$ 1(convexity factor).

For $\mathrm{A} / \mathrm{Ci}$ response curves, the users enters Tleaf, $\mathrm{P}_{\text {atm }}, \mathrm{O}_{2}, \mathrm{~A}, \mathrm{Ci}$ as they are indicated in the light response curve. In addition to these values, limiting factors are assigned as follows: rubisco=1, RUBP regeneration $=2$, and TPU $=3$. After assigning those values, solver in Excel calculates the following: Vcmax, J, TPU, Rd, and $\mathrm{g}_{\mathrm{m}}$ (the maximum carboxylation rate of Rubisco, rate of electron transport for the given light intensity, rate of triose phosphate use, day respiration, and mesophyll conductance, respectively).

For the pot experiment, gas exchange was measured at growth photosynthetically active radiation (PAR), which was $150 \mu \mathrm{mol} \mathrm{m} \mathrm{m}^{-2} \mathrm{~s}^{-1}$ and at saturating PAR $\left(600 \mu \mathrm{mol} \mathrm{m} \mathrm{m}^{-2} \mathrm{~s}^{-1}\right)$. Flow rate in chamber was set to $300 \mu \mathrm{mol} \mathrm{s}^{-1}$ and flow speed set to slow. Six $\mathrm{cm}^{2}$ of leaves were placed in the cuvette chamber.

\subsection{Statistical Methods}

We used ANOVA to examine the effects of CNTs and Ag-QDs on dry weight, photosynthesis, intracellular $\mathrm{CO}_{2}$, stomatal conductance, and transpiration. For the pot experiment, each of these variables were applied as fixed factors, but growth days was a random factor because measurements were taken randomly on different growth days when plants attained $6 \mathrm{~cm}^{2}$ of leaf area. For the petri dish experiments, the variables were applied as response, 
while treatments (control, CNT, and Ag-QD), and growth days $(14,22$, and 30 day) were applied as fixed factors. The interactions between treatments and growth days for each of the variables were also tested. Tukey's test for multiple comparison was run if a $P$-value was significant $(\alpha=0.05)$.

\section{Results}

\subsection{Effects of $75 \%$ solid content CNTs in Petri Dish Experiment}

We found no significant negative effects of the $75 \%$ solid content CNTs at concentrations of $24.93 \mu \mathrm{g} / \mathrm{ml}$ and $53.55 \mu \mathrm{g} / \mathrm{ml}$ in petri dishes. The color of the medium and plant growth is illustrated in Figure 1. There were no significant effects on any gas exchange variables in the first CNT experiment, which includes maximum photosynthetic rates, and photosynthetic responses to light or $\mathrm{CO}_{2}$ (data not shown). Therefore, as would be predicted, we found no significant effects on growth rates and choose to illustrate those data. However, Figures 2 and 3 control curves are statistically the same as found in this first experiment.

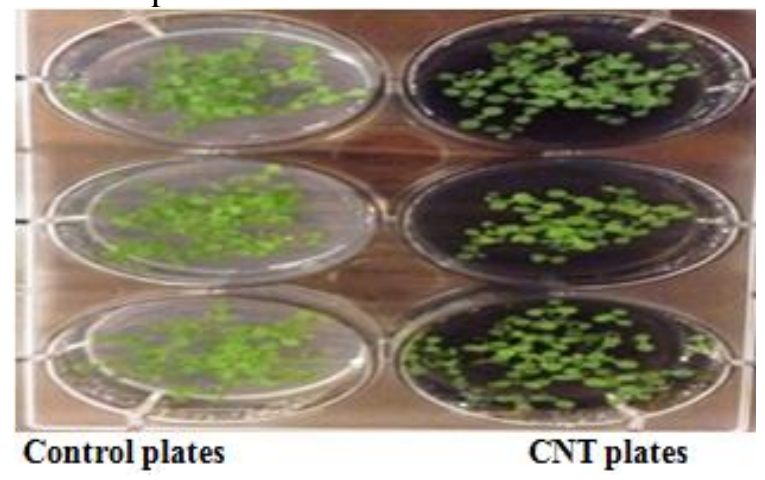

Fig. 1: Photo of A. thaliana plants after 21 days of growth. Petri plates on the left (L) side contain medium without CNTs (Control plates) and on right (R) side contain medium with $95 \%$ CNTs (CNT plates).

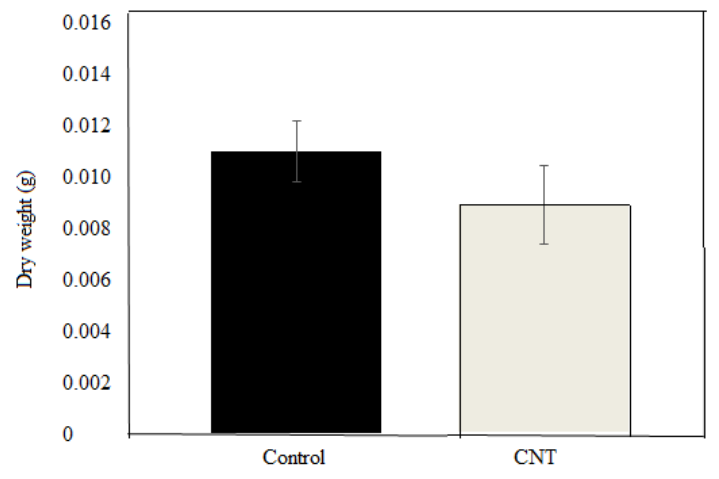

Fig. 2: Mean $( \pm$ SE) dry weight of A. thaliana plants after 21 days of growth in Control grown $(n=12)$ and CNT grown plants $(24.93 \mu \mathrm{g} / \mathrm{ml}, \mathrm{n}=12)$.

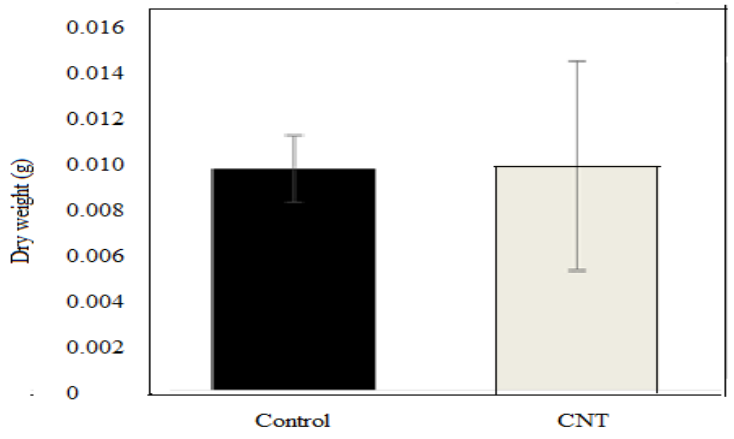

Fig. 3: Mean ( \pm SE) dry weight of $A$. thaliana plants after 21 days of growth in Control grown $(n=12)$ and CNT grown plants $(53.55 \mu \mathrm{g} / \mathrm{ml}, \mathrm{n}=12)$.

\subsection{Effects of 95\% Solid Content CNTs and Ag-QDs in Petri Dish Experiments}

Similar to $75 \%$ CNTs, $95 \%$ CNTs did not have statistically negative effects on plant photosynthetic rates; although there were marginally significant reductions that lead us to examine gas exchange in detail. However, the effects of Ag-QDs on plant photosynthetic rates was very negative. Therefore, we provide a detailed examination of the relative toxicity of these two engineered nanotubes on photosynthetic reactions, even though they are not toxic to the point of killing the plants. Carbon assimilation rate for A. thaliana treated with AgQDs was significantly decreased, with a $56 \%$ reduction compared to control grown plants, when measured at PAR 150, and $500 \mu \mathrm{mol} \mathrm{m}^{-2} \mathrm{~s}^{-1}$ (Table 1). Carbon assimilation rate for CNT grown Arabidopsis was lower by $21 \%$ when measured at PAR $150 \mu \mathrm{mol} \mathrm{m}^{-2} \mathrm{~s}^{-1}$ and by $23 \%$ at PAR $600 \mu$ mol m $\mathrm{m}^{-2} \mathrm{~s}^{-1}$ (Table 1). Carbon assimilation rate reduction was identified further by the results that were obtained from intracellular $\mathrm{CO}_{2}$ concentration (Table 1). Intracellular $\mathrm{CO}_{2}$ concentration was significantly higher in Ag-QD treated plants compared to controls and CNTs; however, CNTs did not statistically affect intracellular $\mathrm{CO}_{2}$ concentration. 
Table 1. Mean carbon assimilation rate and intracellular $\mathrm{CO}_{2}$ concentration

\begin{tabular}{|c|c|c|c|}
\hline Variables & Control & CNT & $\mathrm{Ag}-\mathrm{QD}$ \\
\hline${ }^{i} \mathrm{~A}_{a m b}\left(\mu \mathrm{mol} \mathrm{CO} \mathrm{m}^{-2} \mathrm{~s}^{-1}\right)$ & $4.54=0.315 \mathrm{a}$ & $3.55 \pm 0.224 \mathrm{a}$ & $1.96 \pm 0.127 b$ \\
\hline${ }^{2} \mathrm{~A}_{\operatorname{man}}\left(u \mathrm{~mol} \mathrm{CO}_{2} \mathrm{~m}^{-2} \mathrm{~s}^{-2}\right)$ & $5.92 \pm 0.456 \mathrm{a}$ & $4.52=0.266 \mathrm{a}$ & $2.59=0.171 b$ \\
\hline${ }^{3} \mathrm{Ci}=\left(\mu \mathrm{mol} \mathrm{CO} \mathrm{mol}^{-1}\right.$ air $)$ & $364.00=2.90 \mathrm{a}$ & $364.33=2.42 \mathrm{a}$ & $376.08=2.02$ \\
\hline${ }^{4} \mathrm{Ci}_{\max }\left(u \mathrm{~mol} \mathrm{CO}{ }_{2} \mathrm{~mol}^{-1}\right.$ air $)$ & $357.70=3.37 \mathrm{a}$ & $358.87 \pm 2.52 \mathrm{a}$ & $371.25=2.44$ \\
\hline
\end{tabular}

${ }^{1} \mathrm{~A}_{\mathrm{amb}}$, ambient photosynthesis at light intensity $\mathrm{PPFD}=150 \mu \mathrm{mol} \quad \mathrm{m}^{-2} \mathrm{~s}^{-1}$; ${ }^{2}$ Amax, maximum photosynthesis at $\mathrm{PPFD}=500 \mu \mathrm{mol} \mathrm{m} \mathrm{m}^{-2} \mathrm{~s}^{-1} ;{ }^{3} \mathrm{Ci} \mathrm{amb}$, intracellular $\mathrm{CO}_{2}$ concentration at $\mathrm{PPDF}=150 \mu \mathrm{mol}$ $\mathrm{m}^{-2} \mathrm{~s}^{-1} ;{ }^{4} \mathrm{Ci} \max$, intracellular $\mathrm{CO}_{2}$ concentration at $\mathrm{PPDF}=500 \mu \mathrm{mol} \mathrm{m} \mathrm{s}^{-2}$.

The indicated variables for A. thaliana grown in petri dishes show significant difference $(P<0.05)$ between treatments (control, CNT at $4 \mu \mathrm{g} / \mathrm{ml}$, and $\mathrm{Ag}-\mathrm{QD}$ at $4 \mu \mathrm{g} / \mathrm{ml})$. Values are means $\pm \mathrm{SE}(\mathrm{n}=83)$ and the treatments that do not share the same letters are significantly different.

A. thaliana grown in CNTs and controls had about the same compensation points, and the rate of carbon assimilation matches the rate of respiration (Figure 4). Plants grown in Ag-QDs required a slightly higher light level than plants grown in controls and CNTs to reach the compensation point. Quantum efficiency of photosynthesis, which is represented by the curve slope, and the saturation points (rate of $\mathrm{A}$ at maximum light intensity) were marginally lower in CNT treated plants, while they were significantly lower than controls in Ag-QDs grown plants (Figure 4).

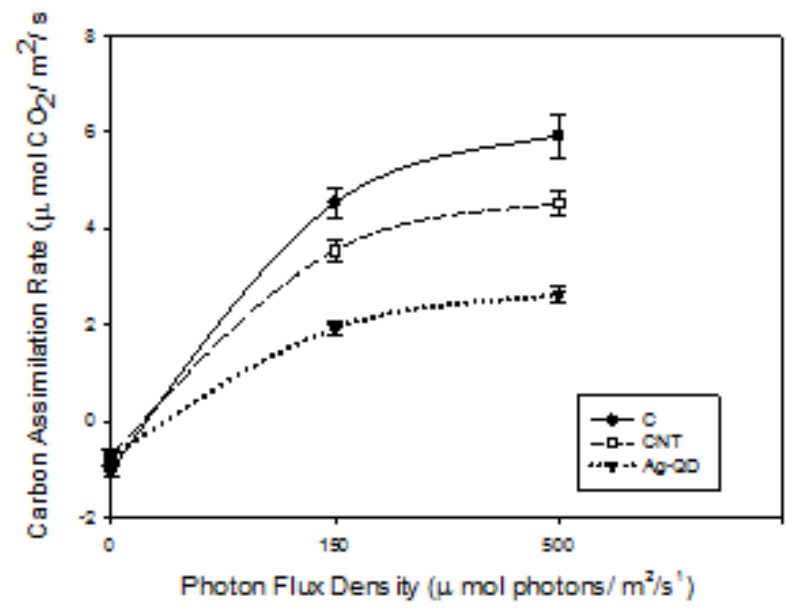

Fig. 4: Mean carbon assimilation responses of $A$. thaliana $(\mathrm{n}=30)$ as a function of treatment and photon flux density. Bars are standard errors. C represents the control plants
Plants grown in Ag-QDs had significantly lower Jmax compared to control plants (p-value $=0.001$ ); however, Jmax in CNT grown plants was not statistically different from controls. In addition, quantum efficiency and convexity factor of Jmax were not statistically affected by these ENPs (Table 2)

Table 2. Mean $( \pm \mathrm{SE})$ for estimated parameters from light response curves.

\begin{tabular}{lcrc}
\hline \multicolumn{1}{c}{ Variables } & Control & CNT & Ag-QD \\
\hline Jmax $\left(\mu \mathrm{mol} \mathrm{m} \mathrm{m}^{-2} \mathrm{~s}^{*}\right.$ & $43 \pm 4.38 \mathrm{a}$ & $33 \pm 2.97 \mathrm{ab}$ & $21 \pm 2.25 \mathrm{~b}$ \\
$\Phi^{*}$ & $0.4358 \pm 0.0169 \mathrm{a}$ & $0.3973 \pm 0.0381 \mathrm{a}$ & $0.3373 \pm 0.0461 \mathrm{a}$ \\
$\Theta^{*}$ & $0.5850 \pm 0.0641 \mathrm{a}$ & $0.4994 \pm 0.0590 \mathrm{a}$ & $0.3815 \pm 0.0606 \mathrm{a}$ \\
\hline
\end{tabular}

*Jmax, maximum rate of electron transport at saturating light; $\Phi$, initial slope of $\mathrm{J} ; \Theta$, convexity factor. A. thaliana $(\mathrm{n}=30)$ grown in petri dishes is significantly different $(P<0.05)$ between treatments (control, CNT at $4 \mu \mathrm{g} / \mathrm{ml}$, and Ag-QD at $4 \mu \mathrm{g} / \mathrm{ml}$ ) in Jmax, but there is no significant difference between treatments in $\Phi$ and $\Theta$.

A. thaliana grown in CNTs reached their compensation point at the same concentration of $\mathrm{CO}_{2}$ as controls, but the compensation point occurred at higher supplemented rate of $\mathrm{CO}_{2}$ in $\mathrm{Ag}$ QDs treated plants than in the other treatments. Carbon assimilation rate response to partial pressure $\mathrm{CO}_{2}$ at 400 and $700 \mu \mathrm{mol} \mathrm{m} \mathrm{m}^{-2} \mathrm{~s}^{-1}$ was decreased in Ag-QD treated plants more than CNTs (Figure 5).

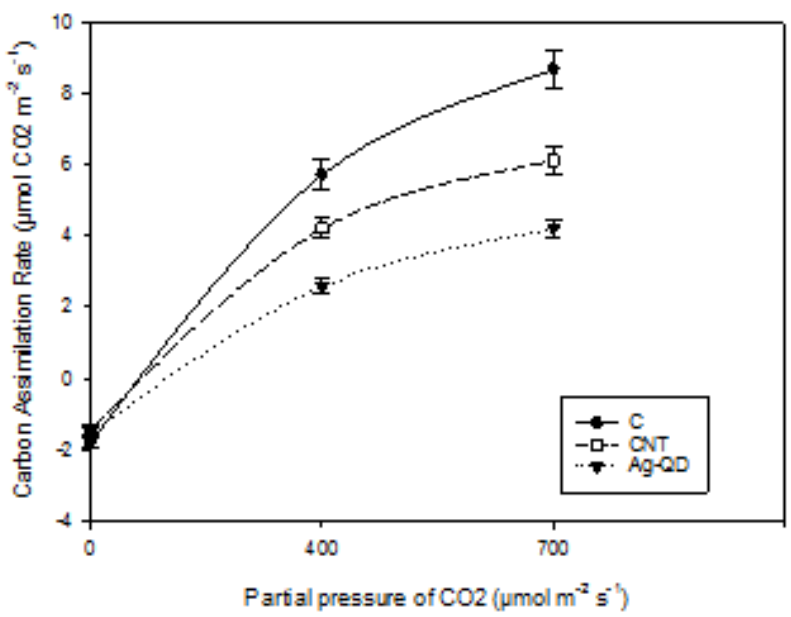

Fig. 5: Carbon assimilation rate response of $A$. thaliana $(\mathrm{n}=30)$ in controls (solid slope), CNTs (dashed slope), and Ag-QDs (dashed slope) in all growth days $(14,22$, and 30) plotted against partial pressure of $\mathrm{CO}_{2}\left(0,400\right.$, and $\left.700 \mu \mathrm{mol} \mathrm{m}^{-2} \mathrm{~s}^{-1}\right)$. SE are shown at each symbol (circle for controls, 
square for CNTs, and triangle for Ag-QDs) that were measured at each light level.

The estimated parameters ( $\mathrm{J}$ and TPU) from A-Cicurve were significantly lower than controls in both CNTs and Ag-QDs grown plant, but Vcmax was significantly low in only Ag-QDs grown plants (Table 3).

Table 3. Mean Values for Estimated Parameters from A-Ci-Curve Fitting Program

\begin{tabular}{lccc}
\hline \multicolumn{1}{c}{ Variables } & Control & CNT & Ag-QD \\
\hline V cmax $\left(\mu \mathrm{mol} \mathrm{m}^{-2} \mathrm{~s}^{-1}\right)$ & $56 \pm 0.18 \mathrm{a}$ & $53 \pm 2.79 \mathrm{a}$ & $45 \pm 2.62 \mathrm{~b}$ \\
$\mathrm{~J}\left(\mu \mathrm{mol} \mathrm{m} \mathrm{s}^{-1}\right)$ & $64 \pm 1.96 \mathrm{a}$ & $53 \pm 2.79 \mathrm{~b}$ & $39 \pm 2.12 \mathrm{c}$ \\
$\mathrm{TPU}\left(\mu \mathrm{mol} \mathrm{m}^{-2} \mathrm{~s}^{-1}\right)$ & $4.4 \pm 0.21 \mathrm{a}$ & $3.5 \pm 0.19 \mathrm{~b}$ & $2.8 \pm 0.16 \mathrm{c}$ \\
\hline
\end{tabular}

\subsection{Effects of $95 \%$ Solid Content CNTs on Plants Grown in Soil in Greenhouse}

The results of gas exchange measurements indicate that A. thaliana grown in soil was not statistically negatively affected by CNTs. While carbon assimilation rate at growth $\left(150 \mu \mathrm{mol} \mathrm{m} \mathrm{m}^{-2} \mathrm{~s}^{-1}\right)$ and saturating light $\left(600 \mu \mathrm{mol} \mathrm{m} \mathrm{m}^{-2} \mathrm{~s}^{-1}\right)$ was lower by $15 \%$ and $12 \%$, respectively, in CNT grown plants relative to controls, the rates were not statistically significantly different. Similarly, intracellular CO2 concentration at $\mathrm{PAR}=150$ and $600 \mu \mathrm{mol} \mathrm{m}^{-2} \mathrm{~s}^{-1}$ was not statistically affected by CNTs.

\section{Conclusion}

Our results indicate that two different CNTs have no to mild toxicity with respect to photosynthetic gas exchange. We can conclude that crop species in the mustard family would probably not be negatively affected in the quantity or nutrient quality of biomass for consumption, which would be consistent with recent published research on $A$. thaliana [7]. For example, decreases in protein given apparent limited effects on rubisco. Indirect effects on secondary chemicals affecting food quality cannot be ruled out per se because the products of photosynthesis could be diverted beyond the light and carbon reactions. Some important results specific to photosynthetic reactions should, however be considered. Photosynthesis rate was slightly decreased compared to controls by $15 \%$ and $12 \%$ at ambient and maximum light intensity respectively for $A$. thaliana grown in soil and by $21 \%$ and 23 at ambient and maximum light intensity respectively for $A$. thaliana grown in agar. A similar response of Polyboroides radiatusand and Sorghum bicolor has been reported [8] where plants grown in agar were more susceptible to nanotube toxicity effects than plants grown in soil, which is also similar to the findings for Sorghum bicolor [9]. We conclude that the reductions in photosynthetic rates were mainly due to effects on Calvin cycle reactions, but the sample size was not large enough to detect statistically significant reductions.

On the other hand, we found that Ag-QDs had a significantly negative effect on variables that limit photosynthetic assimilation. The negative effect of Ag-QDs may occur inside plant leaves. This is unsurprising since QDs have been found to be absorbed through roots leading to leaf stress [10]. Furthermore, It has also been shown that $\mathrm{ZnO}$ reach plant leaves possibly by traveling from root endoderm via apoplastic path way or plasmodesmata in Lolium perenne [11], and that may be the case for Ag-QDs. In addition, argininerich intracellular delivery peptides were identified as way for QDs to travel inside a plant cell [12]. Therefore, in contrast to CNTs, Ag-QDs may negatively impact both the quantity and quality of crop species, which has been established in some research $[8,11]$. For example, Ag-NPs was reported to have a negative effect on absorbing nutrients by blocking intracellular communication or presence of $\mathrm{Ag}^{+}$ions, which were released from Ag-NPs, affecting nutrient carrier proteins function [13]. It is possible that Ag-QDs affect nutrient uptake if they aggregate around plant cells, which is consistent with our data showing significant decrease in the photosynthetic activity.

We found that Ag-QDs reduced carbon assimilation rates by $56 \%$ (Table 1). This would potentially be consistent with effects of ZnO NPs [14]. In that study, chlorophyll a and b contents, net rates of photosynthesis, intercellular $\mathrm{CO} 2$ concentration, leaf stomatal conductance and transpiration rate were reduced by more than $50 \%$ in A. thaliana grown in soil containing ZnO NPs (300 $\mathrm{mg} / \mathrm{L}$ ) for 6 weeks. In addition, they reported that genes associated with oxidative stress and toxicity caused the reduction in chlorophyll expression and carbon assimilation. Consistent with this, our data for A. thaliana grown in MS medium indicated reduction of carbon assimilation rate by $56 \%$, but intracellular $\mathrm{CO}_{2}$ concentration is significantly increased in Ag-QDs treated plant which means that $\mathrm{CO}_{2}$ is not captured efficiently, and this is supported by estimated parameters calculated from $\mathrm{A} / \mathrm{Ci}$ curves.

Responses of photosynthesis to light can be explained by the estimated parameter of Jmax which can be determined by the equation: 


$$
\begin{aligned}
& J=\frac{\left(A+R_{d}\right)\left(4 C_{c}+8_{*}\right)}{\left(C_{c}{ }^{*}\right)} . \\
& J=\frac{J_{\text {max }}+i \sqrt{\left(J_{\max }+i\right)^{2} 4 J_{\max } i}}{2}
\end{aligned}
$$

Jmax provides information about a theoretical maximum electron transport rate that supports $\mathrm{NADP}+$ reduction [15]. We found that Jmax was reduced by $51 \%$ (Table 2); thus, Ag-QDs probably affected electron carrier's occupation and induce inhibition in NADPH production. Electrons that are not delivered to $\mathrm{NADP}^{+}$go to the Mehler reaction and this causes an increase in reactive oxygen species and PS1 photoinhibition. Beside the effect of Ag-QDs on NADPH, Ag-QDs probably affected ATP generation which is an important reaction for producing $\mathrm{H}^{+}$that generate a chemismotic gradient in the grana lamella and permits ATP synthases for interaction between ADP and Pi to make up ATP.

The source of energy (NADPH and ATP), which is regenerated from the light reaction, is the component for running the Calvin cycle. Due to the inhibition of producing NADPH induced by AgQDs, the expected response from Calvin cycle is to fix carbon inefficiently. RUBP-regeneration is the limited photosynthesis associated with electron transport rate that used to support NADP+ reduction [16]. Thus, RUBP-regeneration limited photosynthesis is affected by light condition. The reduction of TPU could be related to genes that were down regulated and involved in transporting carbohydrate. A decrease in this gene expression probably affected the use of TPU for exporting sugar. Therefore, TPU declined in the treated plants.

Importantly, there is no literature reporting the effects of engineered nanoparticles on Calvin cycle reactions. We found that, by using $\mathrm{A} / \mathrm{Ci}$ response curves that Rubisco, RUBP- regeneration, and TPU activity were inhibited under treatment of Ag-QDs. The three limiting photosynthetic factors in $A$. thaliana grown in CNT media were slightly reduced compared with Ag-QDs effect. We also present a relatively novel, easily replicable method for rapid testing of engineered nanoparticles on plant light and carbon reactions, and possibly leaves to feed herbivorous invertebrates [e.g., see 7].

\section{Acknowledgements:}

We thank the Department of Biology and Graduate College at Missouri State University for funding, Brewer Science for providing CNT material, and Rishi Patel for mixing ENP solutions at the Jordan
Valley Innovation Center in Springfield, MO, USA to the concentration specified in this manuscript.

References:

[1] Hegde K., Brar, S.K., Verma M., and Surampalli R.Y. (2016). Current understandings of toxicity, risks and regulations of engineered nanoparticles with respect to environmental microorganisms.

Nanotechnology for Environmental Engineering. 1, 1204-016-0005-4

[2] Solano, R., Patiño-Ruiz, D., and TejedaBenitez, L. (2021 Metal- and metal/oxidebased engineered nanoparticles and nanostructures: a review on the applications, nanotoxicological effects, and risk control strategies. Environ Sci Pollut Res 28, 1696216981.

[3] Zhu. H., Han. J., Xiao. J.Q., and Jin. Y. 2008. Uptake, translocation, and accumulation of manufactured iron oxide nanoparticles by pumpkin plants. Journal of Environmental Monitoring 10, 713-717.

[4] Sudisha J. M., Krishna Paidi K.V.Nagaraja G., Muhammad M., Shashikant S. U.' and Muthusamy G. (2021) Phytotoxicological effects of engineered nanoparticles: An emerging nanotoxicology. Science of the Total Environment. 801, 149809.

[5] Tighe-Neira, R., Gonzalez-Villagra J., NunesNesi A., Inostroza-Blancheteau C. (2022) Impact of nanoparticles and their ionic counterparts derived from heavy metals on the physiology of food crops. Plant Physiology and Biochemistry. 172, 14-23.

[6] JunzhuoLiu J., Zhang H., Yan L., G.Kerr P. G., Zhang S., and Wu Y. (2021) Electron transport, light energy conversion and proteomic responses of periphyton in photosynthesis under exposure to AgNPs. Journal of Hazardous Materials. 401, 23809

[7] Afrin, T., and Wait, D.A (2018). Effects of engineered carbon and silver nanoparticles on gene expression in Plutella xylostella to assess toxicity. Journal of Genetics and Genetic Engineering. 2(1), 9-17.

[8] Aslani, F, Bagheri, S, Muhd Julkapli, N, Juraimi A S, Hashemi FS G, and Baghdadi A. (2014) Effects of engineered nanomaterials on plants growth: an overview. The Scientific World Journal. 2-26.

[9] Shoemaker, A.G., and Wait, D.A. (2020) The Effects of Titanium Dioxide Nanoparticles on the Growth and 
Development of Sorghum Bicolor (L.) Moenech. Advances in Agricluture, Horticulture and Entomology. 2(5), 1-7.

[10] Yeonjong K., Jing W., Qingbo Z., Huiguang Z., Wassim Chehab E., Colvin V.L., Alvarez P.J., and Braam J. (2015) Fluorescence reports intact quantum dot uptake into roots and translocation to leaves of Arabidopsis thaliana and subsequent ingestion by insect herbivores. Environmental Science \& Technology 49: 626-632

[11] Lin, D.H., and Xing B.S. (2008). Root uptake and phytotoxicity of $\mathrm{ZnO}$ nanoparticles. Environment Science. Technology. 42, 5580-5585.

[12] Liu B.R., Li J.F., Lu S.W., Lee H.J., Huang, Y.W., Shannon K.B., and Aronstam R.S. (2010) Cellular internalization of quantum dots noncovalently conjugated with argininerich cell-penetrating peptides. Journal of Nanoscience \& Nanotechnology. 10, 65346543.

[13] Zuverza-Mena N., Armendariz R., PeraltaVidea J.R., and Gardea-Torresdey J.L. (2016) Effects of silver nanoparticles on radish sprouts: Root growth reduction and modifications in the nutritional value. Frontiers in Plant Science. doi: 10.3389/fpls.2016.00090.

[14] Wang X., Yang X., Chen S., Li Q., Wang W., Hou C., and Wang S. (2016). Zinc oxide nanoparticles affect biomass accumulation and Photosynthesis in Arabidopsis. Frontiers in

Plant

Science. https://doi.org/10.3389/fpls.2015.012 $\underline{43}$.

[15] Sharkey T.D. (2016) What gas exchange data can tell us about photosynthesis. Plant,

Cell \& Environment. 39, 1161-1163.

[16] Sharkey T.D., Bernacchi C. J., Farquhar G.D., and Singsaaa E.L. (2007) Fitting photosynthetic carbon dioxide response curves for C3 leaves. Plant, Cell \& Environment 30, 1035-1040.

\section{Creative Commons Attribution License 4.0}

(Attribution 4.0 International, CC BY 4.0)

This article is published under the terms of the Creative Commons Attribution License 4.0

https://creativecommons.org/licenses/by/4.0/deed.en US 